\title{
Current Ripple Minimisation Based on Phase- Shedding of DC-DC Interleaved Converters for EV Charging System
}

\author{
Mohammed A. Alharbi ${ }^{1}$, Mohamed Dahidah ${ }^{2}$, Saleh $\mathrm{Ali}^{3}$, Salaheddine Ethni ${ }^{4}$, Volker Pickert ${ }^{5}$ \\ School of Engineering, Newcastle University, Newcastle upon Tyne, United Kingdom

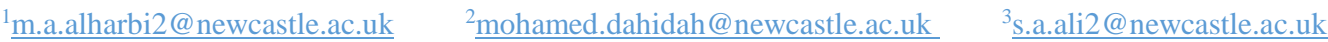 \\ ${ }^{4}$ salaheddine.ethni@newcastle.ac.uk $\quad{ }^{5}$ volker.pickert@newcastle.ac.uk
}

\begin{abstract}
This paper introduces a control scheme to improve efficiency as well as both the input and output current ripples of multiphase interleaved buck converter (IBC), which is suitable for applications that require a wide range of output voltage. The number of phases is dynamically changed throughout the entire range of the output voltage in order to obtain the optimum efficiency and the lowest output ripple possible. The paper demonstrates the proposed approach on a single converter of a fast DC charger module which usually consists of multiple converters connected in input-parallel output parallel (IPOP) configuration. Simulation results show that the proposed technique significantly reduces the output current ripple when compared with the conventional phaseshedding technique while maintaining satisfactory high efficiency across the entire range of the output voltage.
\end{abstract}

Keywords- electric vehicle, fast charging, interleaved buck converter, ripple-free output current

\section{INTRODUCTION}

Nowadays, Electric vehicles (EVs) are gaining significant attention as an environmental-sustainable and cost-effective solution when compared to fossil-fuel conventional cars. The widespread and adaption of EVs will be directly related to the development and availability of fast chargers which should recharge EVs in short times (e.g. <15 minutes). In particular, fast chargers or else, known as (Level 3 or off-board charger), are installed outside the vehicle and hence the name "offboard", mainly in public places [1]. For the purpose of reducing the charging time, the power rating of Level 3 chargers is usually higher than $36 \mathrm{~kW}$ [1], [2].

CHAdeMO and CCS Combo; which are the two most common worldwide standards of Level 3 charging, announced the development of $350-400 \mathrm{~kW}$ charging protocol will be in place by 2020 [3]. However, this charging power requires a high voltage battery system, at least $800 \mathrm{~V}$ inside the EV to reduce the charging current, which has an impact on the charger's cable size. Up to now, no vehicle on the market can accept $350 \mathrm{~kW}$ charging power. However, Porsche has demonstrated an EV (Mission E) that operates at a DC voltage of $800 \mathrm{~V}$ which could support the $350 \mathrm{~kW}$ fast DC charger resulting in a great reduction in the charging times [4]. Yet, most of today's and some future battery-electric vehicles are still using the so-called $400 \mathrm{~V}$ battery voltage system. Table I shows a summary of the battery specifications and the maximum DC charging power of some current and future EVs. This maximum power is obtained by finding the product of the maximum voltage $(\mathrm{V})$ and the maximum amperage $(\mathrm{A})$. For instance, the new CHAdeMO and CCS protocol for $350-400 \mathrm{~kW}$ peak power is enabled with $350-400 \mathrm{~A}$ and $1 \mathrm{kV}$. The most common type of fast charger required by many EVs is the $50 \mathrm{~kW}$ with $125 \mathrm{~A}$ and $400 \mathrm{~V}$. The $150 \mathrm{~kW}$ maintains the same voltage range but increase the charging current to $375 \mathrm{~A}$. Even when a charger is capable of providing high charging power, smaller battery packs are unlikely to be able to accept this much power. For example, if $350 \mathrm{~kW}$ power is available to a smaller $25 \mathrm{kWh}$ pack, battery protection circuits will limit the current and the pack will not accept the higher power [5]. In such a case, the charger needs to operate at lower charging power.

Table I. Comparison of different commercial EVs [6]

\begin{tabular}{|c|c|c|c|}
\hline $\begin{array}{c}\text { Models } \\
(\mathbf{2 0 1 8}-\mathbf{2 0 2 1})\end{array}$ & $\begin{array}{c}\text { Battery } \\
\text { Capacity } \\
{[\mathrm{kWh}]}\end{array}$ & $\begin{array}{c}\text { Range } \\
{[\mathrm{mi}]}\end{array}$ & $\begin{array}{c}\text { Max. DC } \\
\text { Charging Power } \\
{[\mathrm{kW}]}\end{array}$ \\
\hline Peugeot iOn & 16 & 55 & 40 \\
\hline Volkswagen e-Golf & 35.8 & 120 & 40 \\
\hline Nissan Leaf & 40 & 140 & 50 \\
\hline BMW i3s & 42.2 & 140 & 50 \\
\hline Hyundai IONIQ & 30.5 & 120 & 70 \\
\hline Kia e-Soul & 67.1 & 230 & 80 \\
\hline Mercedes EQA & 60 & 215 & 100 \\
\hline Nissan Leaf e+ & 62 & 220 & 100 \\
\hline Tesla Model 3 & 55 & 210 & 120 \\
\hline Audi Q4 e-Tron & 82 & 260 & 125 \\
\hline BMW iX3 & 70 & 200 & 150 \\
\hline Tesla Roadster & 200 & 600 & 250 \\
\hline Audi e-tron GT & 90 & 255 & 350 \\
\hline Porsche Mission E & 90 & 255 & 350 \\
\hline
\end{tabular}

The general configuration of an off-board DC charger module is based on a set of modular converters in order to share the required high output charging power between these connected converters. Among the different converter topologies, the most promising one is the interleaved (multiphase) buck converter (IBC) with reduced output current ripple feature [7].

The converter modules need to be highly efficient to decrease the loss in the process of power transfer to the battery pack. For this purpose, phase-shedding has been introduced to increase the efficiency of such modular DC-DC converters at light-loads [8]. However, deactivating few numbers of modules (or phases) at medium and light load causes an increase in the amplitudes of the input and output current ripples [9], [10]. This disadvantage results in an increase in the EMI noise. Furthermore, this could lead to violating the maximum current and voltage ripples 
requirements specified by most worldwide standards of $\mathrm{EV}$ chargers. In fact, high charge current ripple directly affect the ageing and derating of the EV battery [10]-[13].

Different methods have been previously proposed to reduce the impact of this issue [9], [14], [15]. For example, [9] suggested using a higher output capacitance designed according to the lower number of phases that operate together to meet the output current and voltage ripple specifications. This solution, however, is not very effective as it causes an increase in the system cost and the size of the filter while more decisively eliminating the advantage of using an interleaved topology, which offers the main benefit of reducing the input and output current ripple amplitudes by the ripple cancellation effect. Alternatively, increasing the frequency as the number of phases is reduced at light loads as presented in [14]. However, this technique causes higher power losses as the frequency increases, and consequently, the benefit of phase-shedding for efficiency improvement is lost. Reference [15] proposed a ripple-free output current control strategy for fast dc chargers based on adjusting the dc-link voltage to operate with a specific set of duty cycles. However, the overall efficiency of the proposed topology has not been presented.

This paper introduces a control technique to minimise or even eliminate the output current ripple by activating or deactivating the number of interleaved phases depending on the duty cycle for applications that require a wide output voltage range, such as EV chargers. The proposed control method still retains the benefit of achieving high efficiency at light load condition.

\section{DC CHARGER UNIT BASED ON IBC}

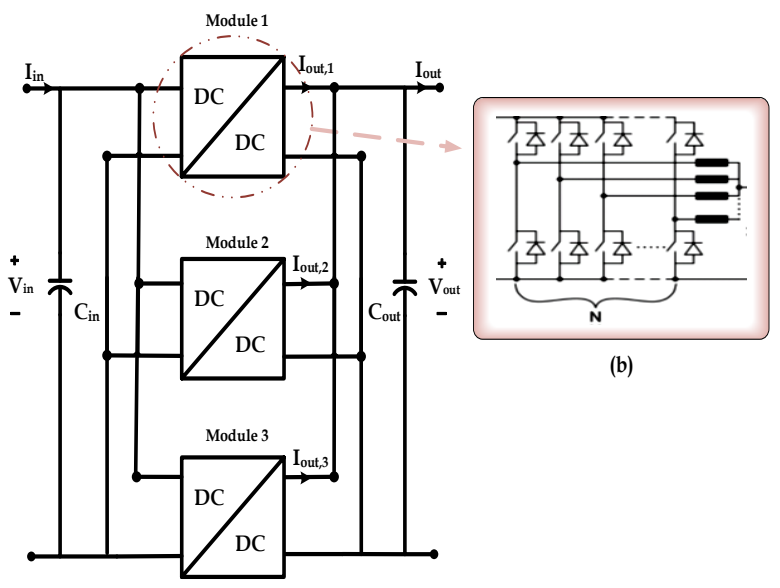

(a)

Figure 1 a) Modular configuration of the dc charger module. b) Generic configuration of a multiphase interleaved buck converter (IBC)

In this paper, a fast DC charger unit is considered as an application. The DC charger unit consists of three modules, each rated at $133.33 \mathrm{~kW}$, compromise of multiple six-phase IBC converters in input-parallel-output-parallel (IPOP) configuration which interface the DC input bus to the output charging bus to meet the desired maximum charging power level of $400 \mathrm{~kW}$ as shown in Fig. 1. The total input current, Iin, and output current, Iout, are shared among the modules of the charger. Hence, Iin and Iout are the sums of the input currents Iin, $\mathrm{N}$ and output currents Iout, $\mathrm{N}$ from each of the modules N. Since the unit is configured in IPOP, the input voltage Vin,N and output voltage Vout,N of each module have the same values as the input voltage, Vin, and the output voltage, Vout, of the DC charger unit. The specifications of each IBC converter module are given in Table II. A commercially available (C2M0045170D) Silicon Carbide ( $\mathrm{SiC})$ MOSFET is considered to be used for the converter modules in this study [16].

Table II. Specifications of an individual IBC cell (case study)

\begin{tabular}{cc}
\hline Parameters & Value \\
\hline Input voltage, $\mathbf{V}_{\text {in }}$ & $1200 \mathrm{~V}$ \\
\hline Output voltage, $\mathbf{V}_{\mathrm{o}}$ & $200-800 \mathrm{~V}$ \\
\hline Maximum output power, $\mathbf{P}_{\text {moy }}$ & $133.33 \mathrm{~kW}$ \\
\hline Maximum output current, $\mathbf{I}_{\text {moy }}$ & $166.67 \mathrm{~A}$ \\
\hline Phase switching frequency, $\mathbf{F}_{\mathrm{s}}$ & $100 \mathrm{kHz}$ \\
\hline Phase Output inductance, $\mathbf{L o}_{\mathrm{o}}$ & $200 \mu \mathrm{H}$ \\
\hline
\end{tabular}

\section{IPOP MODULAR DC-DC CONVERTER WITH SINGLE} INTERLEAVED BUCK CONVERTER

\section{A. Interleaved Multiphase Buck Converter (IBC):}

There are many topologies that can be used in the IPOP modular DC-DC converter, a six-phase IBC is considered in this paper. Interleaving concept as in the IBC topology offers the benefits of reduced input and output current ripples amplitude and increased efficiency by equal distribution of the power between the phases. This results in low rated inductors and power switching devices and consequently reducing the size and cost of the passive components and the overall size and cost of the system. Moreover, the fundamental frequency is multiplied by the number of phases $(N)$ resulting in improving the transient response. Another great advantage of the interleaved configuration is the modularity and simple module configuration as well as the inherent bidirectional power flow [17].

The upper and lower active switches of each phase operate in a complementary manner and each phase is shifted by $360 \% \mathrm{~N}$ from each other. However, the output current is shared between all operating phases. The individual phase's peak-to-peak inductor current is represented by (1), while the combined ripple filtered by the output capacitor is represented in (2).

$$
\begin{array}{r}
\mathrm{I}_{\mathrm{Lo}, \mathrm{PP}}=\frac{\mathrm{V}_{\mathrm{O}} \cdot(1-\mathrm{D})}{\mathrm{f}_{\mathrm{sw}} \cdot \mathrm{L}} \quad[\mathrm{A}] \\
\mathrm{I}_{\mathrm{PP}}=\frac{\mathrm{V}_{\mathrm{O}}}{\mathrm{f}_{\mathrm{Sw}} \cdot \mathrm{L}}\left(\frac{(\mathrm{N} \cdot \mathrm{D}-\mathrm{m}+1) \cdot(\mathrm{m}-\mathrm{N} \cdot \mathrm{D})}{\mathrm{N} \cdot \mathrm{D}}\right) \\
\text { For } \quad \mathrm{m}-1 \leq \mathrm{N} \cdot \mathrm{D} \leq \mathrm{m} \\
\mathrm{m}=\operatorname{Roundup}(\mathrm{N} \cdot \mathrm{D}, 0)
\end{array}
$$

where $f_{s w}$ is the switching frequency, $D$ is the duty cycle of the converter and $L$ is the inductor of each phase. $m$ is the nearest integer that is rounded up from the product of the individual phase duty cycle and the number of active phases. At zero duty cycle, the total output ripple current $\left(\mathrm{I}_{\mathrm{pp}}\right)$ can be normalized to the parameter $K_{N O R M}$ defined in (3) while the ripple current multiplier $K_{C M}$ can be defined as in (4) [18]. 
Therefore, the total output ripple current can be determined by the product of the normalization factor, $K_{N O R M}$ and the ripple current multiplier, $K_{C M}$, which also can be observed from Fig. 3. The capacitor current is the sum of the ripple currents from each individual phase, as defined in (2), and its RMS value is defined in (5) [18].

$$
\begin{gathered}
\mathrm{K}_{\mathrm{NORM}}=\frac{\mathrm{V}_{\mathrm{O}}}{\mathrm{f}_{\mathrm{SW}} \cdot \mathrm{L}} \\
\mathrm{K}_{\mathrm{CM}}=\left(\frac{(\mathrm{N} \cdot \mathrm{D}-\mathrm{m}+1) \cdot(\mathrm{m}-\mathrm{N} \cdot \mathrm{D})}{\mathrm{N} \cdot \mathrm{D}}\right) \\
\mathrm{I}_{\mathrm{O}_{\mathrm{RMS}}}=\sqrt{\frac{\mathrm{I}_{\mathrm{PP}}{ }^{2}}{12}}
\end{gathered}
$$

In the same way, the interleaved configuration presents the advantage of reducing the input ripple current resulting in improving the overall system cost and size of the input capacitors. The RMS value of the ripple current through the input capacitor is expressed by (6), where the $K_{I N, C M}$ is the input-capacitor current multiplier with respect to the output current and the $K_{R A M P, C M}$ is the input-capacitor RMS current multiplier with respect to the inductor current ramp [18].

$$
\begin{gathered}
\mathrm{I}_{\mathrm{in}_{\mathrm{RMS}}}=\sqrt{\mathrm{K}_{\mathrm{IN}, \mathrm{CM}}^{2} \cdot \mathrm{I}_{\mathrm{O}}^{2}+\mathrm{K}_{\mathrm{RAMP}, \mathrm{CM}}^{2} \cdot \mathrm{I}_{\mathrm{LO}, \mathrm{PP}}^{2}} \\
\mathrm{~K}_{\mathrm{IN}, \mathrm{CM}}=\sqrt{\left(\frac{(\mathrm{N} \cdot \mathrm{D}-\mathrm{m}+1) \cdot(\mathrm{m}-\mathrm{N} \cdot \mathrm{D})}{\mathrm{N}^{2}}\right)} \\
\mathrm{K}_{\mathrm{RAMP}, \mathrm{CM}}=\sqrt{\left(\frac{\mathrm{m}^{2}(\mathrm{~N} \cdot \mathrm{D}-\mathrm{m}+1)^{3}+(\mathrm{m}-1)^{2}(\mathrm{~m}-\mathrm{N} \cdot \mathrm{D})^{3}}{12 \mathrm{~N}^{2} \mathrm{D}^{2}}\right)}
\end{gathered}
$$

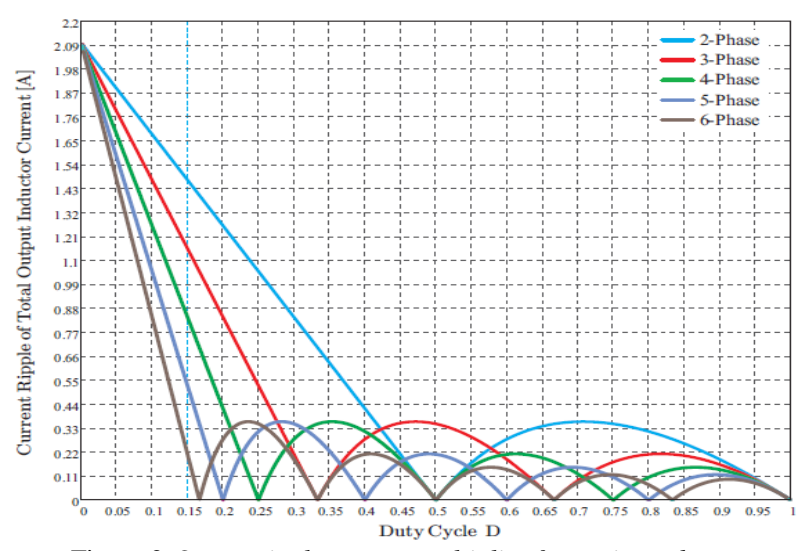

Figure 2 Output ripple current multiplier for various phases

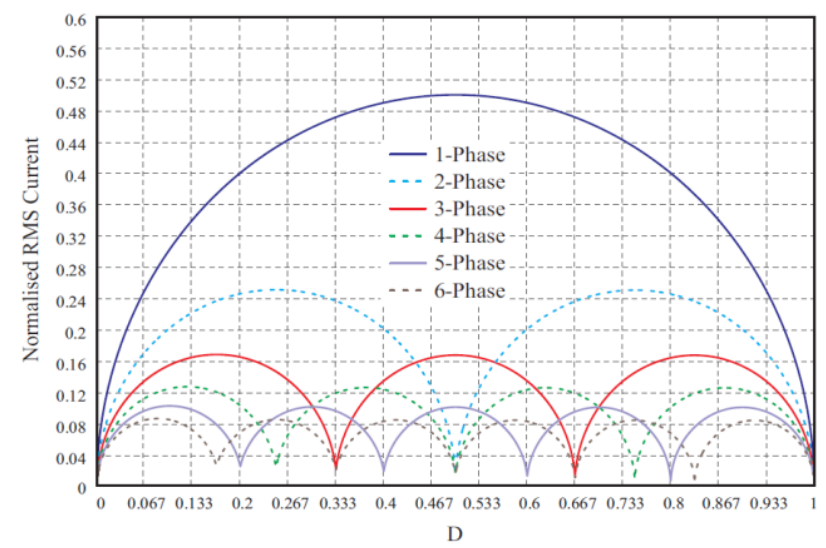

Figure 3 Normalised RMS Current of Input Capacitor of multiphase IBC
The normalised output ripples current and the input ripple current are shown in Fig. 2 and Fig. 3, respectively. The $K_{C M}$ and $K_{I N, C M}$ values are ranged from 0 to 1 and it is a function of the phase duty cycle, number of active channels, and $m$. In addition, as it can be observed from Fig. 2 and Fig. 3, an increase in the number of phases leads to a great reduction in the peak value of the output current ripple. Furthermore, the lower the $K_{C M}$ and $K_{I N, C M}$ values are, the lower the total currents ripple approaching exactly zero ripples when the duty cycle is near the critical points for the selected phase [19]. Thus, a six-phase model is considered in this paper as it presents more options to operate at one of these zero points which leads to an optimal design with the smallest and fewest number of output capacitors.

However, one of the disadvantages of IBC is that it suffers from reducing the efficiency at light load. The reduction in efficiency is mainly resulted due to the great number of switches presents in the converter module which causes high switching losses. Switching losses are insignificant at nominal to high power but at lighter power, switching losses become significant, thus reducing the efficiency of the system [9].

\section{B. Power Losses in Multiphase IBC}

The losses of a multiphase converter can be expressed as the total losses of a single phase, i.e. synchronous buck converter, multiplied by the number of phases $N$, except for the output capacitor loss as it is shared by all the multiple phases. Fig. 4 shows the main power losses distribution for a synchronous DC-DC buck converter. The single buck module consists of a half bridge and the output inductor. The input and output capacitors are shared by all the interleaved modules [19]-[21].

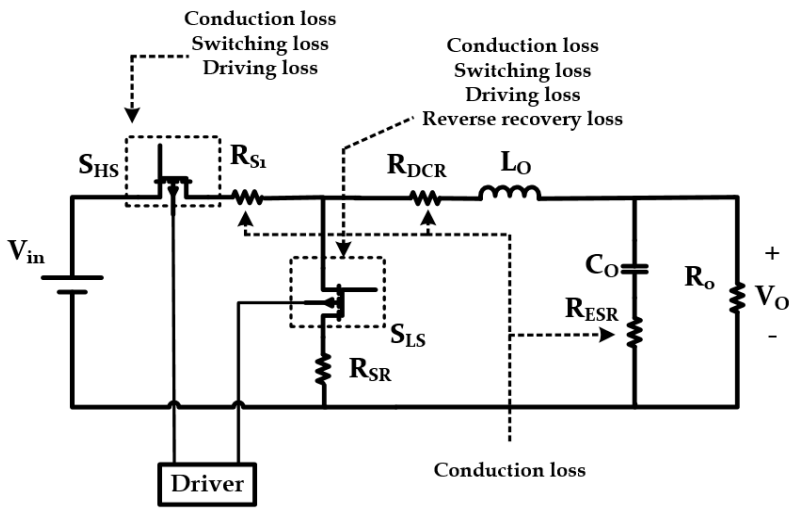

Figure 4 Summary of power loss distribution for a dc-dc buck converter

A large portion of power losses in a single phase of an IBC is dominated by the switching devices e.g. SiC MOSFET's parasitic. The total gate capacitance $\mathrm{Q}_{\mathrm{g}}$ of an active switch must be charged to turn the switch ON. The power loss for this portion can be defined as follows:

$$
\mathrm{P}_{\text {driving }}=V_{g} \cdot Q_{g} \cdot f_{s w}
$$

Another main parasitic of an active switch, which contributes to the conduction losses of the converter, is the on-state resistance $\mathrm{R}_{\mathrm{ds} \text {-on }}$, where the conduction loss is defined as:

$$
P_{\text {conduction }}=I_{\text {rms }}^{2} \cdot R_{d s-o n}
$$


The diode reverses recovery losses occur in the lower switch $\mathrm{S}_{\mathrm{LS}}$ when the current commutates from the diode to $\mathrm{S}_{\mathrm{HS}}$ when the $\mathrm{S}_{\mathrm{HS}}$ is turned $\mathrm{ON}$ and is expressed as follows:

$$
\mathrm{P}_{\mathrm{rr}}=\frac{1}{2} \mathrm{Q}_{\mathrm{rr}} \cdot \mathrm{f}_{\mathrm{sw}} \mathrm{V}_{\mathrm{in}}
$$

where $Q_{r r}$ is the reverse recovery charge as indicated in the data sheet of the chosen actives switch device. For a buck operation mode, the upper switch $\mathrm{S}_{\mathrm{HS}}$ contributes to the major portion of the switching loss, which can be expressed as follows:

$$
\mathrm{P}_{\mathrm{rr}}=\frac{1}{2} \cdot \mathrm{f}_{\mathrm{sw}} \cdot \mathrm{V}_{\text {out }} \cdot \mathrm{I}_{\mathrm{HS}}\left(\mathrm{t}_{\mathrm{r}}+\mathrm{t}_{\mathrm{f}}\right)
$$

where $I_{H S}$ is the upper switch current when the device is ON. $t_{r}$ and $t_{f}$ are the current fall time and the voltage rise time of $\mathrm{S}_{\mathrm{HS}}$, respectively, both of which can be estimated from the device data sheets. Another conduction losses are produced from the parasitic resistances of the inductors and capacitors of the converter and are expressed as follow:

$$
\begin{aligned}
& \mathrm{P}_{\mathrm{L}-\text { cond }}=\mathrm{I}_{\mathrm{rms}}^{2} \cdot \mathrm{R}_{\mathrm{ESR}} \\
& \mathrm{P}_{\mathrm{C}-\text { cond }}=\mathrm{I}_{\mathrm{rms}}^{2} \cdot \mathrm{R}_{\mathrm{ESR}}
\end{aligned}
$$

For such high-power application, the use of Wide bandgap semiconductors devices such as Silicon Carbide ( $\mathrm{SiC}$ ) and Gallium Nitride (GaN) offers lower losses when compared to Silicon (Si) technology due to their capability of withstanding higher voltage levels, allowing faster switching and lower conduction losses [22].

\section{PHASE-SHEDDING CONTROL SCHEME AND ITS IMPACT ON THE CAPACITOR OUTPUT CURRENT RIPPLE}

At high power, the conduction loss represents the main losses which can be reduced by activating all the phases and share the output current among all $N$ phases so that high efficiency can be attained. In the contrast, when the power or load becomes light, the power processed by each phase is significantly reduced; if all the phases are still operating, the switching loss, reverse-recovery loss, inductor core loss, etc. still exist in all phases resulting in reducing the efficiency. In this way, deactivating or activating a certain number of phases to their optimal efficiency results in an efficiency improvement of the entire system [23]. Phase-shedding control can achieve a good performance and high efficiency particularly, at light power conditions.

\section{A. Efficiency optimisation by sequential phase switching}

In the classic approach of phase-shedding control, the operational phase number is determined according to the output current. Few numbers of phases are used at low output currents down to a single phase to minimise the switching losses resulted by the active switch devices in the converter. Conduction losses begin to dominate over switching losses as the load current increases. Consequently, more phases are activated or deactivated to keep efficiency as high as possible [21], [23]. To activate or deactivate the phases at the optimum set point, the intersection between neighbouring efficiency curves, as depicted in Fig. 5, have to be selected. These are the threshold values, which can be obtained by undertaking loss analysis, where the efficiency becomes higher by adding on dropping a phase. The conventional hysteresis control can be used where the two set-point thresholds are defined [24].

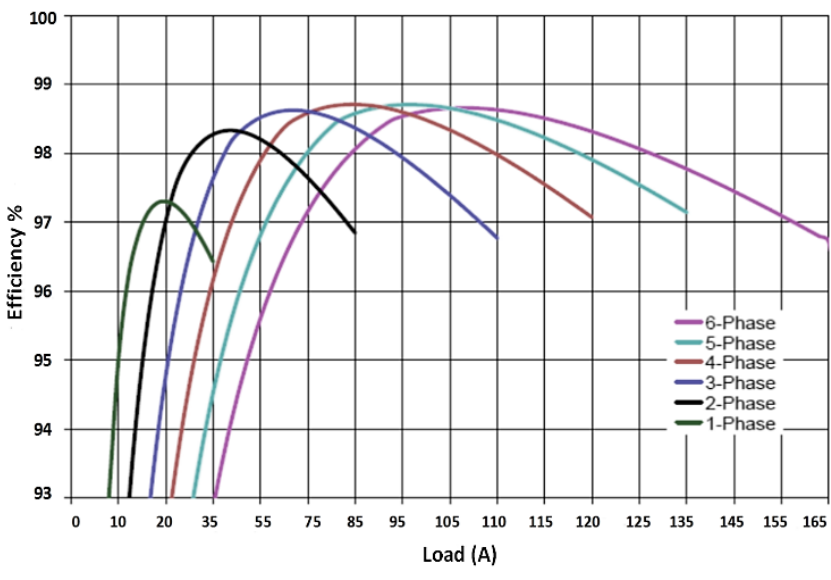

Figure 5 Efficiency with a different phase number

\section{B. Capacitor Output Current Ripple Consideration}

Phase-shedding technique has been widely used in different applications, due to its advantage in improving the efficiency. However, deactivating few numbers of phases at medium and light load can also affect the ripple cancellation effect as well in a negative way, particularly, the input and output current ripples. This is due to the fact that the phaseshift among the phases changes too when the number of active phases changes with the load and consequently, ripple cancellation effect results by interleaving is reduced [9], [10].

This drawback can cause an increase in the EMI noise and losing the benefit on EMI filters designed within the converter module while also affecting the regulation of the output voltage. In fact, for a battery charging application, for instance, the maximum current and voltage ripples are set at $1 \%$ and $5 \%$ of the nominal value, respectively by most worldwide standards of EV chargers. This is due to the fact that high current ripple results in reducing the lifespan among the charging and discharging processes of the EV battery [10], [12], [13], [25].

\section{PRoposed TECHNIQUe For Minimising OUtPUT CURRENT RIPPLE}

\section{A. Effects of interleaving on current ripples}

One major advantage of interleaving several converter channels (e.g. interleaved buck converter) is the ripple cancellation which results in a significant reduction of both the input and outputs current ripples. Consequently, a small inductance can be used to improve the transient response which in turns lowers the amount of capacitance needed to keep the output voltage within tolerance. In addition, lower current ripples can maintain a long-life cycle of a battery for a battery charging application [13], [26].

The degree of output and input current ripples reduction depends on the number of interleaved phases and the duty cycle, as aforementioned. At particular duty cycles, when $D$ is at scaling factor of $D=1 / N$, the output current ripples are totally eliminated, as shown in Fig. 4. Hence, in theory for fixed output voltage application the output filter capacitor is not required at all when operating at one of these points, resulting in a compact converter size and faster response time. However, in practical operation, noise, line transients, load transients, and natural variations in the duty cycle could affect the current ripple. Hence, the output capacitors are not 
avoidable to be used. Yet, the IBC enables employing less bulky capacitors and in some cases, electrolytic capacitors can be replaced by film capacitors, which have a quite low failure rate and high reliability [27].

For wide output voltage range applications, there is a potential to reduce or even eliminate the output current ripple by activating or deactivating the number of interleaved phases depending on the duty cycle.

\section{B. Proposed voltage control strategy}

Since the converter is designed to operate with wide output voltage range, (e.g. $200 \mathrm{~V}$ to $800 \mathrm{~V}$ ) to cater for the needs of majority of modern EVs for the considered application in this paper, then the current ripple can be reduced or eliminated by determining the duty cycle and selecting the number of phases operating in each module that achieves the lowest ripple possible. The selection also considers the output current to achieve the highest possible efficiency for the entire load conditions.

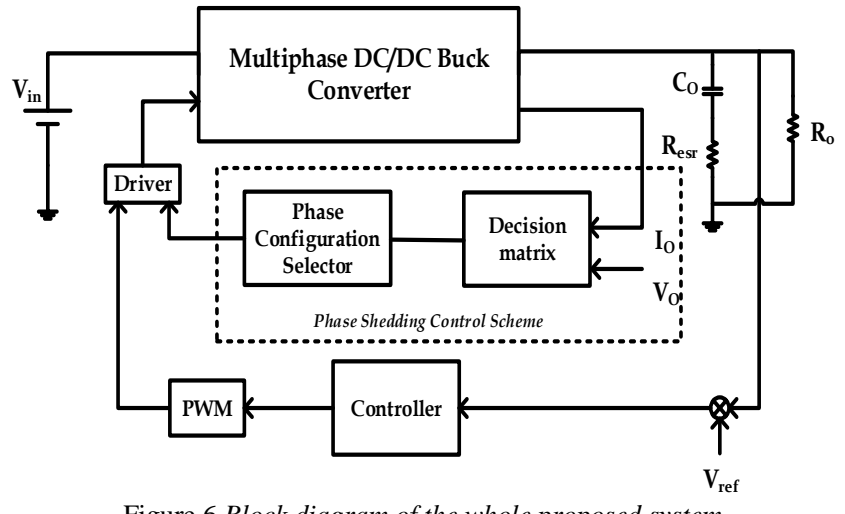

Figure 6 Block diagram of the whole proposed system

The proposed phase shedding control algorithm is shown in Fig. 6. Unlike the classic control approach of phaseshedding which depends only on the output current, the selection of the number of phases in the proposed method is also a function of the output voltage to ensure the lowest output ripple current and the highest efficiency possible.

Considering the case study given in Table II with an output voltage ranged from $200 \mathrm{~V}$ to $800 \mathrm{~V}$, the proposed low to ripple-free output current technique is explained. The proposed method aims at obtaining the lowest value of the ripple current multiplier $K_{C M}$, which directly affects the resultant output current ripple seen by the output capacitor. In addition, the selection of the number of phases takes into account the maximum current flowing in each phase according to the required output current. The first two phases of the six phases in a single converter module will always be operating as the current ripple when only two phases are $\mathrm{ON}$ will be quite excessive as shown in Fig. 4. The improvement in the current ripple for a wide output voltage range application is usually noticed when three-phase or more are operating.

The proposed control algorithm is illustrated in Table III. Considering the sensed output voltage, it can be seen that the number of phases is selected according to the lowest ripple that can be achieved with the corresponding duty cycle. However, the maximum current flowing on each phase requires to be also considered to achieve the highest efficiency and safe operation. Since the maximum output current obtained from a single module converter is $166.67 \mathrm{~A}$, for this particular example, therefore the condition has been set as almost half of this current to ensure keeping the maximum current of each phase below $40 \mathrm{~A}$, which is a general design guideline for the maximum phase current [28].

Table III Control algorithm for output voltage and output current

\begin{tabular}{|c|c|}
\hline \multicolumn{2}{|c|}{ Case A: $200 \leq V_{\text {out }} \leq 250$} \\
\hline $\begin{array}{c}\text { For } I_{\text {out }} \leq 83 \\
\text { Select four-phase }\end{array}$ & $\begin{array}{c}\text { For } I_{\text {out }}>83 \\
\text { Select five-phase }\end{array}$ \\
\hline \multicolumn{2}{|c|}{ Case B: $251 \leq V_{\text {out }} \leq 300$} \\
\hline $\begin{array}{c}\text { For } I_{\text {out }} \leq 83 \\
\text { Select four-phase }\end{array}$ & $\begin{array}{c}\text { For } I_{\text {out }}>83 \\
\text { Select five-phase }\end{array}$ \\
\hline \multicolumn{2}{|c|}{ Case C: $301 \leq V_{\text {out }} \leq 350$} \\
\hline $\begin{array}{c}\text { For } I_{\text {out }} \leq 83 \\
\text { Select four-phase }\end{array}$ & $\begin{array}{c}\text { For } I_{\text {out }}>83 \\
\text { Select five-phase }\end{array}$ \\
\hline \multicolumn{2}{|c|}{ Case D: $351 \leq V_{\text {out }} \leq 400$} \\
\hline $\begin{array}{c}\text { For } I_{\text {out }} \leq 83 \\
\text { Select three-phase }\end{array}$ & $\begin{array}{c}\text { For } I_{\text {out }}>83 \\
\text { Select six-phase }\end{array}$ \\
\hline \multicolumn{2}{|c|}{ Case E: $401 \leq V_{\text {out }} \leq 450$} \\
\hline $\begin{array}{c}\text { For } I_{\text {out }} \leq 83 \\
\text { Select three-phase }\end{array}$ & $\begin{array}{c}\text { For } I_{\text {out }}>83 \\
\text { Select six-phase }\end{array}$ \\
\hline \multicolumn{2}{|c|}{ Case F: $451 \leq V_{\text {out }} \leq 500$} \\
\hline $\begin{array}{c}\text { For } I_{\text {out }} \leq 83 \\
\text { Select three-phase }\end{array}$ & $\begin{array}{c}\text { For } I_{\text {out }}>83 \\
\text { Select five-phase }\end{array}$ \\
\hline \multicolumn{2}{|c|}{ Case G: $501 \leq V_{\text {out }} \leq 550$} \\
\hline $\begin{array}{c}\text { For } I_{\text {out }} \leq 83 \\
\text { Select four-phase }\end{array}$ & $\begin{array}{c}\text { For } I_{\text {out }}>83 \\
\text { Select five-phase }\end{array}$ \\
\hline \multicolumn{2}{|c|}{ Case H: $551 \leq V_{\text {out }} \leq 600$} \\
\hline $\begin{array}{c}\text { For } I_{\text {out }} \leq 83 \\
\text { Select four-phase }\end{array}$ & $\begin{array}{c}\text { For } I_{\text {out }}>83 \\
\text { Select six-phase }\end{array}$ \\
\hline \multicolumn{2}{|c|}{ Case I: $601 \leq V_{\text {out }} \leq 650$} \\
\hline $\begin{array}{c}\text { For } I_{\text {out }} \leq 83 \\
\text { Select four-phase }\end{array}$ & $\begin{array}{c}\text { For } I_{\text {out }}>83 \\
\text { Select six-phase }\end{array}$ \\
\hline \multicolumn{2}{|c|}{ Case J: $651 \leq V_{\text {out }} \leq 700$} \\
\hline $\begin{array}{c}\text { For } I_{\text {out }} \leq 83 \\
\text { Select five-phase }\end{array}$ & $\begin{array}{c}\text { For } I_{\text {out }}>83 \\
\text { Select six-phase }\end{array}$ \\
\hline \multicolumn{2}{|c|}{ Case $K: 701 \leq V_{\text {out }} \leq 750$} \\
\hline $\begin{array}{c}\text { For } I_{\text {out }} \leq 83 \\
\text { Select five-phase }\end{array}$ & $\begin{array}{c}\text { For } I_{\text {out }}>83 \\
\text { Select six-phase }\end{array}$ \\
\hline \multicolumn{2}{|c|}{ Case L: $751 \leq V_{\text {out }} \leq 800$} \\
\hline $\begin{array}{c}\text { For } I_{\text {out }} \leq 83 \\
\text { Select five-phase }\end{array}$ & $\begin{array}{c}\text { For } I_{\text {out }}>83 \\
\text { Select six-phase }\end{array}$ \\
\hline
\end{tabular}

\section{Simulation Results}

A simulation model of the proposed converter is developed using Matlab/Simulink, where all the parasitic components in the circuit are taken into account. The goal of the simulation study is to show the performance of the voltage and current controllers along with the proposed phaseshedding control scheme. For the simulation, the structure of Fig. 6 is used. The tasks of the controller part are to regulate the output voltage and ensure equal current sharing between all active phases while considering the correct phase shift between each active phase. According to the output voltage and output current conditions, the phase configuration part is programmed to output 1 as long as the phase requires to operate, and once the phase requires to shed, it is programmed to output 0 . 
The proposed control scheme at both light load and medium load conditions, which are the two critical regions of operation, are presented in this section. For simplicity, the two different scenarios are presented in a single graph, where the medium load condition is presented with $V_{\text {out }}=600 \mathrm{~V}$ $I_{\text {out }}=100 \mathrm{~A}$, and the light load condition is presented with $V_{\text {out }}=300 \mathrm{VI}_{\text {out }}=30 \mathrm{~A}$, as shown in Fig. 7. The input voltage is fixed at $1200 \mathrm{~V}$.

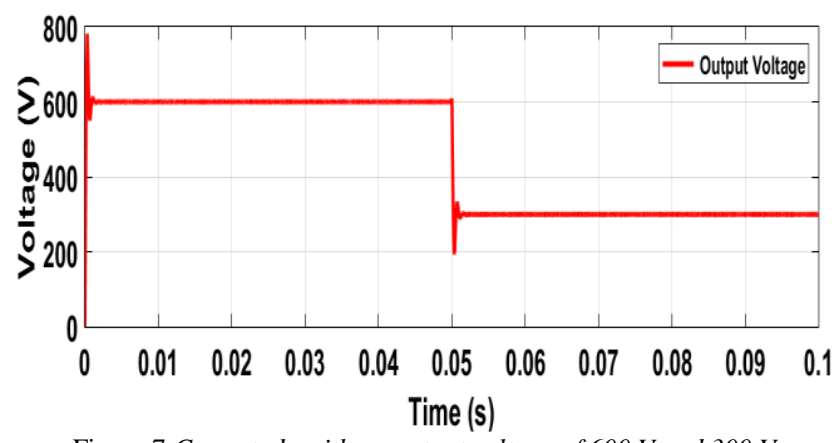

Figure 7 Case-study with an output voltage of $600 \mathrm{~V}$ and $300 \mathrm{~V}$

Fig. 8 represents the inductor current of each phase obtained using the classic phase-shedding control where the number of active phases is determined according to the output current only. With referring to the efficiency curve in Fig. 5, five-phase are operated when the output current is $100 \mathrm{~A}$ whereas only two-phase are switched on when the output current is $30 \mathrm{~A}$ in order to maintain high efficiency of the system at the light and medium load conditions. Even though almost $98 \%$ is achieved for the two cases, excessive output current ripple is resulted due to the reduction of the number of operating phases as shown in Fig. 9. The output ripple is further increased at the light load case as less number of phases are operating.

In contrast, Fig. 10 shows the inductor current employing the proposed phase-shedding scheme where the selection of the number of active phases are determined according to both the output voltage and output current. Once the output voltage and output current are sensed, the optimum number of phases are selected according to Table III, which would results in the lowest ripple possible while maintaining high efficiency. For the medium load case with an output voltage of $600 \mathrm{~V}$, sixphase is switched on because this results in obtaining zero ripples in the output current as shown in Fig. 11. Similarly, four-phase is switched on for the light load case resulting in zero ripples as well in the output current. The efficiency in the proposed control method is reduced slightly by almost $1 \%$ because a higher number of phases are conducting. Yet, a great improvement in the total output current ripple is achieved.

The phase shifts between phases must be computed depending on the number of active phases e.g. $360^{\circ} / \mathrm{N}$ to ensure ripple cancellation among the operating phases. In addition, the compensator must be able to control the change in the power stage of the converter arising from changing the number of phases which results in a modification of the power converter's transfer function. Poor transient response is obtained if the controller is designed in the same way as without phase-shedding. Hence, more advanced compensation schemes, e.g. adaptive control techniques, are expected to be used to obtain better performance.

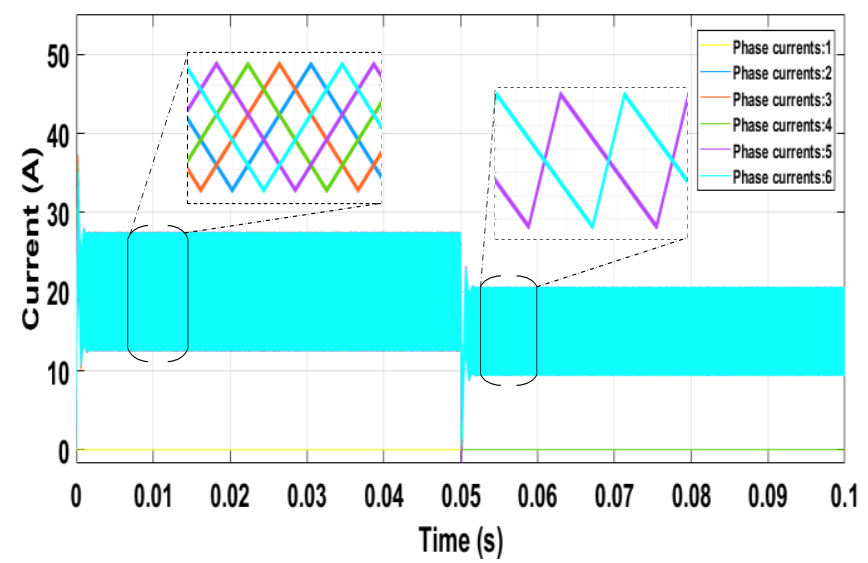

Figure 8 Inductor current using the classic phase-shedding technique.

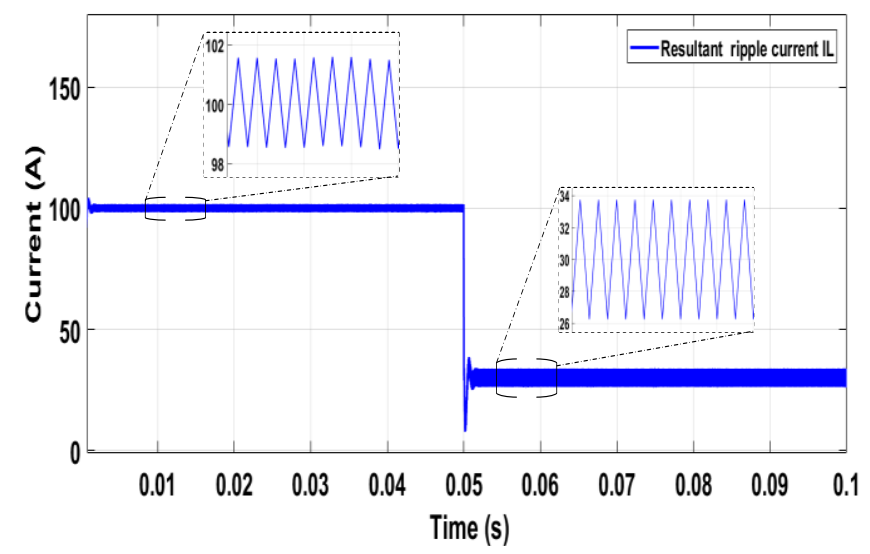

Figure 9 Output inductor using the classic phase-shedding technique.

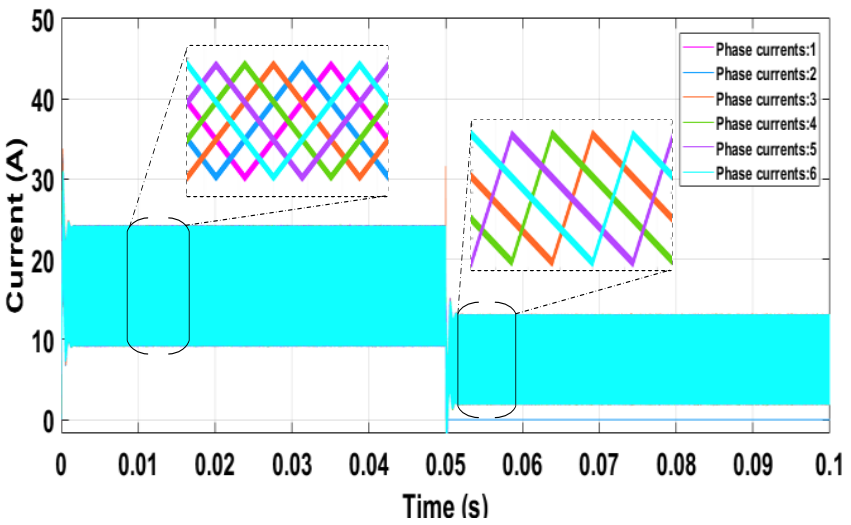

Figure 10 Inductor current using the proposed phase-shedding technique.

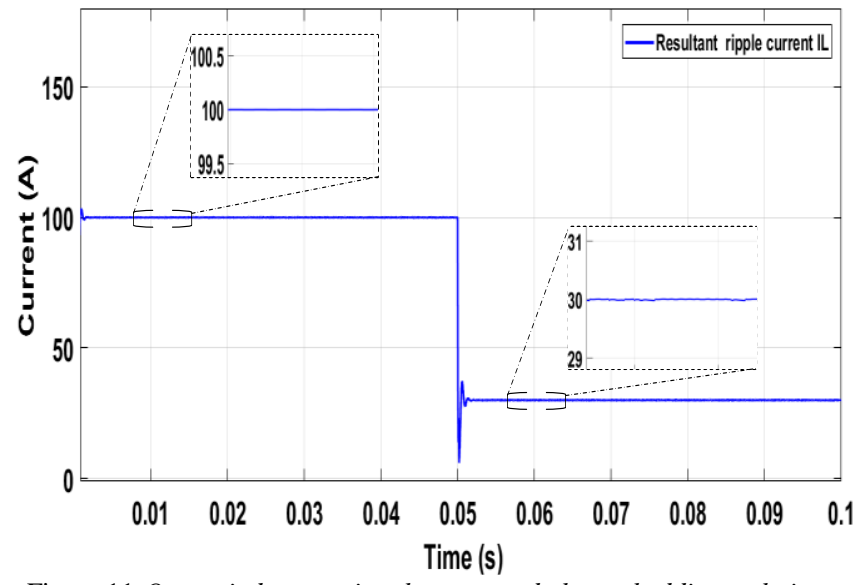

Figure 11 Output inductor using the proposed phase-shedding technique. 


\section{CONCLUSION}

In this paper, a new phase-shedding approach for multiphase interleaved converter has been proposed. With interleaving of several phases for any DC-DC converter topologies, the output and input currents ripples can be eliminated or reduced according to the selected duty ratio or the number of operating phases. The proposed control approach aims to select the optimum number of phases that lead to the lowest possible current ripples for both, the input and output current at any duty cycle while maintaining high efficiency. The proposed control scheme can be applied to any interleaved DC-DC converters. Due to the great improvement in the output ripple current, the interleaved buck converter topology, in an IPOP configuration, along with the proposed control scheme can be used as a DC charger unit for EV battery, which requires low charging output current in order to increase the lifespan of the EV battery.

\section{REFERENCES}

[1] L. Rubino, C. Capasso, and O. Veneri, "Review on plug-in electric vehicle charging architectures integrated with distributed energy sources for sustainable mobility," Appl. Energy, vol. 207, pp. 438-464, Dec. 2017

[2] S. Habib, M. M. Khan, F. Abbas, L. Sang, M. U. Shahid, and H. Tang, "A Comprehensive Study of Implemented International Standards, Technical Challenges, Impacts and Prospects for Electric Vehicles," IEEE Access, vol. 6, pp. 13866-13890, 2018

[3] "Chademo Brochures," Chademo Association \& Protocol, Mar-2018. [Online]. Available: https://www.chademo.com/about-us/brochures/

[4] C. Jung, "Power Up with 800-V Systems: The benefits of upgrading voltage power for battery-electric passenger vehicles," IEEE Electrification Mag., vol. 5, no. 1, pp. 53-58, Mar. 2017.

[5] M. Nicholas and D. Hall, "Lessons learned on early electric vehicle fast-charging deployments," International Council on Clean Transportation, Washington D.C., USA, White Paper, Jul. 2018.

[6] "EV Database," EV Database. [Online]. Available: https://evdatabase.uk/compare/cheapest-electric-vehicle.

[7] D. Aggeler et al., "Ultra-fast DC-charge infrastructures for EVmobility and future smart grids," in 2010 IEEE PES Innovative Smart Grid Technologies Conference Europe (ISGT Europe), 2010, pp. 1-8.

[8] Y. Ting, S. de Haan, and J. A. Ferreira, "Efficiency improvements in a Single Active Bridge modular DC-DC converter with snubber capacitance optimisation," in 2014 International Power Electronics Conference (IPEC-Hiroshima 2014 - ECCE ASIA), 2014, pp. 2787 2793.

[9] P. Zumel, C. Fernández, A. de Castro, and O. García, "Efficiency improvement in multiphase converter by changing dynamically the number of phases," in 2006 37th IEEE Power Electronics Specialists Conference, 2006, pp. 1-6.

[10] C. Wang, M. Xu, F. C. Lee, and Z. Luo, "Light load efficiency improvement for multi-channel PFC," in 2008 IEEE Power Electronics Specialists Conference, 2008, pp. 4080-4085.

[11] F. C. Lee, Shuo Wang, Pengju Kong, Chuanyun Wang, and Dianbo $\mathrm{Fu}$, "Power architecture design with improved system efficiency, EMI and power density," in 2008 IEEE Power Electronics Specialists Conference, 2008, pp. 4131-4137.

[12] S. D. Breucker, K. Engelen, R. D'hulst, and J. Driesen, "Impact of current ripple on Li-ion battery ageing," in 2013 World Electric Vehicle Symposium and Exhibition (EVS27), 2013, pp. 1-9.

[13] K. Uddin, A. D. Moore, A. Barai, and J. Marco, "The effects of high frequency current ripple on electric vehicle battery performance," Appl. Energy, vol. 178, pp. 142-154, Sep. 2016.

[14] F. Chen and D. Maksimović, "Digital control for efficiency improvements in interleaved boost PFC rectifiers," in 2010 TwentyFifth Annual IEEE Applied Power Electronics Conference and Exposition (APEC), 2010, pp. 188-195.

[15] K. Drobnič, G. Grandi, M. Hammami, R. Mandrioli, A. Viatkin, and M. Vujacic, "A Ripple-Free DC Output Current Fast Charger for Electric Vehicles Based on Grid-Tied Modular Three-Phase Interleaved Converters," in 2018 International Symposium on Industrial Electronics (INDEL), 2018, pp. 1-7.
[16] "Power Products | Wolfspeed." [Online]. Available: https://www.wolfspeed.com/power/products

[17] O. Garcia, P. Zumel, A. de Castro, and A. Cobos, "Automotive DCDC bidirectional converter made with many interleaved buck stages," IEEE Trans. Power Electron., vol. 21, no. 3, pp. 578-586, May 2006.

[18] C. Cheung and R. Staffhorst, "Multi-Phase Power Conversion For Routers and PC Peripherals Up To 100A," Intersil, Application Note ISL6558EVAL1, Nov. 2002.

[19] M. Gerber, J. A. Ferreira, I. W. Hofsajer, and N. Seliger, "Interleaving optimization in synchronous rectified DC/DC converters," in 2004 IEEE 35th Annual Power Electronics Specialists Conference (IEEE Cat. No.04CH37551), 2004, vol. 6, pp. 4655-4661 Vol.6.

[20] W. Qiu, C. Cheung, S. Xiao, and G. Miller, "Power Loss Analyses for Dynamic Phase Number Control in Multiphase Voltage Regulators," in 2009 Twenty-Fourth Annual IEEE Applied Power Electronics Conference and Exposition, 2009, pp. 102-108.

[21] J. Su and C. Liu, "A Novel Phase-Shedding Control Scheme for Improved Light Load Efficiency of Multiphase Interleaved DC-DC Converters," IEEE Trans. Power Electron., vol. 28, no. 10, pp. 47424752 , Oct. 2013.

[22] J. Rabkowski, D. Peftitsis, and H. Nee, "Silicon Carbide Power Transistors: A New Era in Power Electronics Is Initiated," IEEE Ind. Electron. Mag., vol. 6, no. 2, pp. 17-26, Jun. 2012.

[23] L. Fleischli, S. Lemofouet, and A. Rufer, "Multichannel DC-DC Converter's Efficiency Optimisation by variable Number of active Channels," in IECON 2006 - 32nd Annual Conference on IEEE Industrial Electronics, 2006, pp. 2581-2586.

[24] H. Lim, "A phase shedding technique for PV system based on interleaved boost converter," Master's Thesis, The University of New South Wales, Sydney, NSW, Australia, 2016.

[25] F. C. Lee, and, and and, "Power architecture design with improved system efficiency, EMI and power density," in 2008 IEEE Power Electronics Specialists Conference, 2008, pp. 4131-4137.

[26] M. P. Varghese, A. Manjunatha, and S. Kumar, "Performance analysis of multiphase buck converter for VRMs using phase shedding technique," in 2016 Biennial International Conference on Power and Energy Systems: Towards Sustainable Energy (PESTSE), 2016, pp. 15.

[27] J. Liu, "Investigation of Multiphase Power Converter using Integrated Coupled Inductor Regarding Electric Vehicle Application," PhD Thesis, University of Kassel, Kassel, Germany, 2015.

[28] C. Parisi, "Multiphase Buck Design from Start to Finish, Part 1," Texas Instruments, Application Report SLVA882, Apr. 2017. 